\title{
Barriers to Online Learning in the Time of COVID-19: A National Survey of Medical Students in the Philippines
}

\author{
Ronnie E. Baticulon ${ }^{1,2}$ - Jinno Jenkin Sy ${ }^{3}$ (D) Nicole Rose I. Alberto ${ }^{3}$ - $\cdot$ Maria Beatriz C. Baron ${ }^{3}$. \\ Robert Earl C. Mabulay ${ }^{3}$ - Lloyd Gabriel T. Rizada ${ }^{3}$ (1) . Christl Jan S. Tiu ${ }^{3}$ - Charlie A. Clarion ${ }^{4}$ (D) \\ John Carlo B. Reyes ${ }^{5}$ (D)
}

Accepted: 1 February 2021 / Published online: 24 February 2021

(c) International Association of Medical Science Educators 2021

\begin{abstract}
Introduction In March 2020, the coronavirus disease 2019 (COVID-19) pandemic forced medical schools in the Philippines to stop face-to-face learning activities and abruptly shift to an online curriculum. This study aimed to identify barriers to online learning from the perspective of medical students in a developing country.

Methods The authors sent out an electronic survey to medical students in the Philippines from 11 to 24 May 2020. Using a combination of multiple-choice, Likert scale, and open-ended questions, the following data were obtained: demographics, medical school information, access to technological resources, study habits, living conditions, self-assessment of capacity for and perceived barriers to online learning, and proposed interventions. Descriptive statistics were calculated. Responses were compared between student subgroups using nonparametric tests.

Results Among 3670 medical students, 93\% owned a smartphone and $83 \%$ had a laptop or desktop computer. To access online resources, $79 \%$ had a postpaid internet subscription while $19 \%$ used prepaid mobile data. Under prevailing conditions, only 1505 students (41\%) considered themselves physically and mentally capable of engaging in online learning. Barriers were classified under five categories: technological, individual, domestic, institutional, and community barriers.

Discussion Medical students in the Philippines confronted several interrelated barriers as they tried to adapt to online learning. Most frequently encountered were difficulty adjusting learning styles, having to perform responsibilities at home, and poor communication between educators and learners. By implementing student-centered interventions, medical schools and educators play a significant role in addressing these challenges during the COVID-19 pandemic and beyond.
\end{abstract}

Keywords COVID-19 $\cdot$ Online learning $\cdot$ Philippines $\cdot$ Undergraduate medical education

\section{Background}

Ronnie E. Baticulon

rebaticulon@up.edu.ph

1 Department of Anatomy, University of the Philippines College of Medicine, Manila, Philippines

2 Division of Neurosurgery, Department of Neurosciences, Philippine General Hospital, Manila, Philippines

3 University of the Philippines College of Medicine, Manila, Philippines

4 Section of Pulmonary Medicine, Department of Internal Medicine, Philippine General Hospital, University of the Philippines, Manila, Philippines

5 National Institutes of Health, University of the Philippines Manila, Manila, Philippines
The coronavirus disease 2019 (COVID-19) pandemic disrupted undergraduate medical education worldwide. During the early part of 2020, when little was known about the disease and no effective treatment or vaccine was available, medical schools in different countries had to suspend classroom teaching and remove students from their clinical placements [1]. These drastic measures intended to ensure safety of learners and educators [2], curb viral transmission in higher education institutions and hospitals [3], conserve personal protective equipment for essential staff [4], and reduce the teaching load of physicians deployed at the pandemic's frontlines [5]. To sustain medical education, it became necessary for medical schools to pivot to online learning_also called e-learning, web-based learning, or 
internet-based learning $[6,7]$-as their primary means of curriculum delivery. In a short span of time, medical educators had to adapt and innovate, designing online learning experiences to substitute for lost hours that would have been spent in the classroom [8], laboratory [9], or patient's bedside [10].

Howlett defined online learning as "the use of electronic technology and media to deliver, support, and enhance both learning and teaching and involves communication between learners and teachers utilizing online content" [11]. The advantages of using online learning in medical education include improved accessibility of information, ease of standardizing and updating content, cost-effectiveness, accountability, and enhancement of the learning process, wherein students are motivated to be active learners [7, 12]. Online learning can provide students with foundational knowledge and confidence before exposure to real or standardized patients [13]; it has been used effectively to teach evidence-based medicine [14] and to facilitate interprofessional education [15]. A recent systematic review suggested that online learning for undergraduate health professions was equivalent and possibly even superior to traditional methods of curriculum delivery [16]. The high risk of bias among several included studies, however, precluded the authors from drawing definitive conclusions.

In low- and middle-income countries, online learning has the potential to (1) address faculty shortage, expanding the reach of medical educators and improving their efficiency; (2) improve access to health professions' training, increasing the number of health workers and encouraging their retention in regional units; and (3) facilitate collaboration with institutions that have more resources [17]. Notwithstanding, in survey studies during the COVID-19 pandemic in India [18], Pakistan [19], Nepal [20], Jordan [21], and Libya [22], the majority of medical students had a negative perception or expressed dissatisfaction towards online learning.

In the Philippines, a low-middle-income country in Southeast Asia, classes in all levels were suspended in midMarch of 2020, after the government had put the country's largest island Luzon and other major cities under lockdown [23]. Halfway into the second semester, medical schools had to cease all face-to-face learning activities. Medical students were removed from clinics, wards, intensive care units, and emergency departments. Local and international electives were cancelled. The national internship program was likewise suspended, and the physician licensure exam postponed indefinitely.

Forced to abruptly transition to an online curriculum, each medical school crafted its own guidelines on learning activities, revised assessment measures, and set promotion policies. Consequently, the learning experiences of students varied among medical schools nationwide. In an open letter posted on social media, the student network of the Association of Philippine Medical Colleges called for the suspension of online learning and termination of the ongoing semester, citing difficulties that the students had encountered, particularly poor internet connection, limited access to gadgets, and lack of study space at home [24].

The utilization of and capacity for online learning in Philippine medical schools had not been described before. In this paper, we aimed to comprehensively identify and describe the challenges to online learning from the perspective of medical students during the COVID19 pandemic. Regmi and Jones previously examined papers on e-learning in health sciences education and categorized barriers under four themes: poor motivation and expectations, resource-intensiveness, not being suitable for all disciplines or contents, and lack of information technology skills [25]. Focusing on developing countries, Frehywot et al. cited inadequate infrastructure, lack of face-to-face interaction, inadequate technical support staff, financial costs of maintaining the platform, and time commitment required from teachers as major challenges [17]. From the standpoint of managers and educators, also important were resistance to change [26] and lack of institutional strategies and support [27]. It must be pointed out that these studies evaluated online learning as part of planned curricular changes or under controlled circumstances.

We hypothesized that during the COVID-19 pandemic, medical students in the Philippines faced socioeconomic and cultural barriers, in addition to limited access to technological resources. It is crucial to have targeted interventions that address these challenges in low- and middle-income countries, where the need to continuously train skilled health workers is also greatest [28].

\section{Methods}

We conducted a nationwide cross-sectional study among medical students in the Philippines from May 11 to 24, 2020, through an electronic survey in Google Forms (Google LLC, Mountain View, California). At that time, online classes had been ongoing for 8 weeks, and most medical schools were nearing the end of their academic year. Face-to-face learning activities would remain suspended in all medical schools for the rest of year 2020. During the study period, the Philippines reported an average of 210-246 new confirmed COVID-19 cases per day, reaching a peak 7-day average of 4477 new cases in August 16 [29]. Based on World Bank data [30], the country had an estimated population of 108 million in 2019. 


\section{Philippine Medical Education}

The Doctor of Medicine program in the Philippines takes 4 years [31]. The first 2 years consist mainly of didactic teaching, when students learn basic or foundational sciences. Clinical placements usually begin in third year, although clinical sciences may be introduced through lectures, case presentations, simulation activities, and patient encounters as early as first year. During the fourth year, medical students complete 12 months of clinical clerkship, with required rotations in internal medicine, pediatrics, surgery, and obstetrics-gynecology. Other courses that must be integrated in the curriculum include history of medicine, research, medical informatics, legal medicine, medical jurisprudence, bioethics, leadership and management, and interprofessional education.

There is marked variability in medical curricula throughout the country [32]. Medical schools may implement a curriculum that is subject- or discipline-based, organ- or problem-based (i.e., integrated), community-based, or any other innovative curriculum. Regardless, students must attain the learning outcomes that the Commission on Higher Education set for the Doctor of Medicine program [31]. To obtain a medical license, graduates must undergo 1 year of internship and then pass a written examination that covers 12 subjects.

\section{Survey Instrument}

We initially conducted a focus group discussion with medical students from the University of the Philippines, searched official school websites for announcements on changes being implemented in Philippine medical schools due to the COVID-19 crisis, and reviewed relevant literature. Using these background data, we developed a 23-item questionnaire (see Supplementary Material A) that collected demographics, medical school information, access to technological resources, study habits, current living conditions, and views on online learning.

Using a 4-point Likert scale (strongly disagree, disagree somewhat, agree somewhat, strongly agree), we asked the participants: (1) whether they considered themselves physically and mentally capable of studying online for the rest of the semester; (2) whether medical schools should give a passing grade to all their students (i.e., mass promotion); (3) whether they had enough time and resources for online learning; and $(4,5)$ whether the resources of their schools and the skills of their educators were adequate. We listed ten barriers to online learning and asked respondents to select how frequently they have encountered each barrier. In openended questions, we probed for any additional barriers that the students may have faced, and asked for their proposed interventions.

The primary investigator (REB) drafted the survey instrument. It was pilot tested among medical students (NRIA,
MBCB, RECM, LGTR, JJS, and CJST) and revised several times, incorporating critical reviews from medical educators (CAC and JCBR). The research unit of the Department of Anatomy provided a technical review for face validity. The study protocol was submitted to the University of the Philippines Manila Research Ethics Board, which granted a certificate of exemption (UPMREB 2020-281-EX).

We distributed the survey link through social media (Twitter, Facebook, Instagram) and the Association of Philippine Medical Colleges Student Network. We contacted organizations to share the link among students in their respective schools. Our survey was open to students from first to fourth year levels. Participation was voluntary, anonymity was guaranteed, and consent was obtained.

\section{Data Analysis}

At the end of the data collection period, de-identified data were exported to Stata/IC 16.1 for Mac (Stata Corp, College Station, Texas). We stratified the data based on demographics and medical school information, calculating the frequencies and percentages of categorical variables. In the selfassessment of capacity for online learning, the responses were converted to their numeric equivalents from 1 to 4 , and these were used to get the mean and median responses for each subgroup. We analyzed differences between subgroups using Kruskal-Wallis test, with post hoc analysis using Dunn's multiple nonparametric pairwise tests. A $P$ value $<0.05$ was considered statistically significant. For the rest of the Likert scale questions and the list of barriers to online learning, we computed the frequencies and percentages of responses.

\section{Results}

\section{Survey Respondents}

We received a total of 3813 responses. We removed 75 (2\%) that were duplicate entries based on email addresses or student numbers, and $68(2 \%)$ that were deemed invalid because of missing information or because respondents were not medical students. Hence, we included 3670 responses (96\%) in the data analysis. This represented $15 \%$ of the estimated 25,000 medical students in the Philippines.

The exact number and distribution of medical students enrolled for academic years 2019-2020 were not available at the time of study completion. In lieu of this, we compared our nonrandom study sample with the total population of first-time examinees of the physician licensure exam [33] in the last 5 years (see Table 1). Our sample had a higher percentage of students enrolled in public medical schools ( $16 \%$ vs. $14 \%, p=0.001$ ). The representation of the different regions also differed $(p<0.001)$. Of the 55 medical schools 
recognized by the Commission on Higher Education, 54 (98\%) were represented in this survey. The median number of respondents per institution was 42 (range 1-293), with 23 schools having 50 respondents or more.

\section{Demographics and Access to Technological Resources}

More students from lower year levels answered the survey: 1153 (31\%), first year; 1015 (28\%), second year; 863 (24\%), third year; and $639(17 \%)$, fourth year. Mean age was $23.8 \pm 2.4$ years. At a ratio of $2.2: 1$, females $(n=2468,67 \%)$ outnumbered males $(n=1109,30 \%)$. There were $39(1 \%)$ who identified as nonbinary. Among the respondents, 169 $(5 \%)$ were married or partnered in a long-term relationship while $82(2 \%)$ had children. The majority of medical students belonged to the low-income and lower-middle-income brackets ( $n=1029,28 \%$ and $n=1665,45 \%$, respectively). One out of six $(n=651,18 \%)$ received financial aid.

On device ownership, 3421 (93\%) had a smartphone, $2311(63 \%)$ had a tablet, and $3043(83 \%)$ had a laptop or desktop computer. Most students $(n=2916,79 \%)$ subscribed to a postpaid internet service, but three out of five subscribers described their connection as slow and/ or unreliable. Accessing the internet primarily through prepaid mobile data was still common at $19 \%(n=696)$. While most students lived at home with their family during the pandemic $(n=2856,78 \%)$, there were $610(17 \%)$ who remained in their temporary residence near their school.

\section{Capacity for Online Learning}

Under prevailing circumstances, only $41 \%$ of medical students $(n=1505)$ considered themselves capable of adapting to online learning. The responses of the students were similar, regardless of medical school classification $(p=0.79)$ or location $(p=0.96)$ (see Table 2$)$. Factors that significantly affected the self-assessment of students were year level $(p<0.001)$, age $(p=0.002)$, gender $(p<0.001)$, annual family income $(p<0.001)$, academic standing $(p<0.001)$, internet access $(p=0.03)$, and number of hours previously spent on online learning $(p<0.001)$. Students who were less likely to consider themselves capable of online learning were in their first or second year of medical school, 29 years old or younger, female or nonbinary, or from a family in a low- or middle-income bracket. Negative responses were also more common among those who reported a lower academic standing or previously spent fewer hours on online learning every week.

Figure 1 summarizes the responses to the Likert scale questions. The majority of the respondents $(n=2651,72 \%)$ believed that medical schools affected by the COVID-19 pandemic should promote all students, with 77\% $(n=2813)$ saying that they had enough time and resources to prepare for the next year level. Almost half $(n=1720,47 \%)$ agreed that their teachers had the requisite skills and resources, while $44 \%(n=1604)$ said that their schools were equipped to support online teaching.

\section{Barriers to Online Learning}

Among barriers to online learning, the most frequently encountered were difficulty adjusting learning styles, having to perform responsibilities at home, and poor communication or lack of clear directions from educators (see Fig. 2). Approximately two-thirds of the respondents always or often confronted these barriers. Lack of physical space conducive for studying and mental health difficulties were also common. The data showed that the availability of fast and reliable internet connection was a bigger concern than either device ownership or technical aptitude. One out
Table 1 Comparison of study population with first-time examinees of the national physician licensure examination from August 2014 to March 2019

\begin{tabular}{|c|c|c|c|c|c|c|}
\hline \multicolumn{2}{|c|}{ Medical school category } & \multicolumn{2}{|l|}{ Current study } & \multicolumn{2}{|c|}{$\begin{array}{l}\text { Board examinees, } \\
2014 \text { to } 2019^{*}\end{array}$} & \multirow[b]{2}{*}{$P$ value } \\
\hline & & $\begin{array}{l}\text { Number of } \\
\text { students } \\
(N=3,670)\end{array}$ & Percentage & $\begin{array}{l}\text { Number of } \\
\text { students } \\
(N=19,124)\end{array}$ & Percentage & \\
\hline \multirow[t]{2}{*}{ Classification } & Public & 592 & $16 \%$ & 2682 & $14 \%$ & 0.001 \\
\hline & Private & 3078 & $84 \%$ & 16,442 & $86 \%$ & \\
\hline \multirow[t]{4}{*}{ Location } & $\begin{array}{l}\text { National } \\
\text { Capital } \\
\text { Region }\end{array}$ & 1726 & $47 \%$ & 10,492 & $55 \%$ & $<0.001$ \\
\hline & Luzon & 728 & $20 \%$ & 3276 & $17 \%$ & \\
\hline & Visayas & 721 & $20 \%$ & 3928 & $21 \%$ & \\
\hline & Mindanao & 495 & $13 \%$ & 1428 & $7 \%$ & \\
\hline
\end{tabular}

*Source: Professional Regulation Commission 
of ten students always or often lacked basic needs such as food, water, medicine, and security.

We elicited additional challenges to online learning in the free-text responses. These are summarized in Table 3. Together with our initial list, the barriers were grouped under five categories: (1) technological, which pertain to hardware, software, and internet connectivity; (2) individual, which involve students' learning styles, physical, and mental health; (3) domestic, which are concerns at home or within the family, including financial distress; (4) institutional, which revolve around administration, medical curriculum, school resources, and educator skills; and (5) community barriers, which include lockdown restrictions, infrastructure challenges, and sociopolitical issues. Students recommended different interventions to address these barriers. A table of illustrative responses is included in Supplementary Material B.

\section{Discussion}

This national survey of 3670 medical students from 54 schools in the Philippines revealed that students, regardless of geographic location or demographic subgroup, encountered several barriers as they tried to adapt to online learning during the COVID-19 pandemic.

In their review that evaluated e-learning interventions for medical education in developing countries, Barteit et al. found that most studies were small-scale and had examined projects in their pilot stages [34]; this phenomenon coined "pilotitis" has hindered the development of standards for e-learning in low-resource settings. Further, research in developing countries has focused mostly on technological (e.g., cost, access, software design) or contextual challenges (e.g., knowledge management, economy and funding, sociocultural norms), often failing to provide a comprehensive view or whole-system perspective [35]. It is important to identify any additional enablers and barriers, which may not have been present in the highincome countries where these teaching strategies were often developed and first evaluated.

Before the COVID-19 pandemic, medical schools in the Philippines had never had to implement online learning on this massive scale. The Commission on Higher Education's guidelines on the Doctor of Medicine program had not set standards and minimum resource requirements for online learning $[31,36]$. This unprecedented situation presented an opportunity to critically examine the state of medical education nationwide, systematically evaluate the effectiveness of online curricula in a developing country, and formulate contingency plans for similar circumstances in the future. Our paper provided important baseline data for these efforts.

We showed that the number of medical students with limited access to technological resources was not negligible.
One out of five students did not have a computer, and an identical proportion had to rely on prepaid mobile data for connectivity. Roughly one out of twenty used only a smartphone. Power interruptions, weak infrastructure, and internet costs restricted the students' access to online content. Despite these figures, a striking finding was that students did not perceive technological limitations to be most important, as can be seen in Fig. 2. A higher percentage of students had experienced challenges relating to their personal study habits, situation at home, and interaction with educators. Studies on online learning in developing countries often concentrated on students' limited access to devices and the internet $[20,37,38]$. Our results implied that providing gadgets to the students, as some medical schools had rightfully and already done, might not be enough to ensure successful learning outcomes, especially if other barriers were not adequately addressed.

Our data also confirmed that traditional teaching methods (i.e., teacher-led, classroom-based learning activities) continued to be the norm in Philippine medical education. Almost three-fourths of the respondents (74\%) indicated that prior to the pandemic, no more than $8 \mathrm{~h}$ were allocated to self-directed learning in their weekly schedules. As a result, the abrupt shift in curriculum delivery, which required a simultaneous adjustment in learning styles, had been difficult for the students. To illustrate, in lieu of giving a lecture, some teachers only provided handouts filled with text or PowerPoint files without a voice narration. In this scenario, visual learners and auditory learners, as elaborated by Fleming and Mills [39], would be expected to have learning difficulties.

Respondents said that studying topics on their own was more difficult compared with studying topics that teachers had previously discussed in a lecture. Thus, to comprehend the same amount of information, students needed more hours in the current setup. To address these concerns, educators should minimize the cognitive load of learning activities to what is essential. Multimedia learning tools should be engaging and entertaining, but at the same time, devoid of clutter and distracting content [40]. Enhancing interactivity, use of practice exercises, repetition of study material, and providing feedback are recommended to improve learning outcomes [41].

Medical students who previously spent fewer hours studying online were less likely to agree that they could cope. Many admitted that they lacked self-discipline and drive to study. Educators must understand learners' needs, motivations, and past experiences to maintain engagement in an online curriculum [12]. To achieve academic success, students need to be guided in developing self-regulated learning strategies, which include time management, metacognition, critical thinking, and effort regulation [42]. As students become more familiar with online learning 
modalities, they may be expected to adapt and have a more favorable perception towards online education [43].

The pandemic had also caused psychological stress among the students, making it difficult for them to focus on studying. They expressed feelings of anxiety, burnout, loneliness, homesickness, grief, and hopelessness. The students worried about online assessments, future plans in medical school, possible delays in training, and safety of their families from COVID-19. Overall, $86 \%$ of the students reported experiencing some degree of mental health difficulty. Similarly high rates have been reported among medical students in Turkey [44], Japan [45], and Australia [46], and their concerns mirrored that of Filipino medical students.

We noted that difficulty adjusting learning styles and mental health concerns were more common among female and nonbinary respondents, those in the first 2 years of medical school, and those with a lower academic standing. This may partly account for observed differences in selfassessment of capacity for online learning. A large study among medical students in Japan recommended initiation of mental wellness programs that targeted enhancing self-esteem and self-efficacy, with focus on resilience training [45]. Living in urban areas, economic stability, and living with parents have been shown to be protective factors against anxiety among students in China [47].

It was evident that more time spent at home did not necessarily equate to more time for academic work. There were students who could not concentrate because they were constantly exposed to conflict among family members. Even in the absence of domestic dispute, some found it hard to turn down conversations with parents or siblings. Filipino families are characterized by cohesiveness and reciprocity, and the most educated members are often expected to act as caregivers or household heads [48-50]. In the current health crisis, many medical students had been relegated to this role. They took care of sick relatives, were in charge of buying food and supplies, or had to work for extra income. Moreover, although the learning environment may be virtual, physical space remained vital. Having a quiet study area, with the same comfort provided by a classroom or library, was a privilege not available to all.

Medical students doubted the readiness of their schools to transition to online learning. They cited lack of guidelines, unfair policies, haphazard class schedules, low quality of teaching materials, ineffective teaching strategies, and excessive class requirements. For comparison, academic medical centers in Singapore had clearly laid out allowable undergraduate education activities and assessments depending on their pandemic alert level [51]. In New York, medical schools formulated a strategic plan that allowed students to complete graduation requirements on time and facilitated early transition to residency [2].
Communication channels needed improvement. Students said that their views were not being heard, and they lamented the lack of appropriate action from school administrators in response to student feedback regarding the conduct of online learning. They also voiced out the need to interact with peers, with whom they could exchange insights, resources, and opinions. The key to collaborative learning in the online environment is to harness existing and emerging technologies such as e-mail, message boards, chats, collaborative work spaces (e.g., Google Docs, Wiki spaces), and even social media $[7,12]$.

Students were concerned that they were not learning essential skills or getting ample patient exposure, a sentiment that is echoed around the globe $[4,52]$. When classes were suspended, third and fourth year medical students were shifted to virtual clinical rotations. Their learning activities included lectures on the diagnosis and treatment of important diseases, virtual case presentations and small-group discussions, and attendance at online department conferences. Although medical students could safely participate in telemedicine, most hospitals had not yet set up their units during the study period. Virtual bedside teaching rounds have also been described [53] and could be explored in hospitals equipped with the requisite gadgets. Because of paucity of well-designed studies, the impact of online learning on improving performance behavior and patient outcomes remains subject to debate [54]. No amount of online learning could replace the actual experience of delivering a newborn, assisting in a trauma laparotomy, or looking after a patient with diabetic ketoacidosis from admission to discharge. All medical schools should therefore have a roadmap for students' return to clinics.

The shifts in Philippine medical education had happened with the economic consequences of COVID-19 in the background. Unemployment rate in the country was at record high [55]. Analysis of the students' responses had revealed the pervasive nature of this problem: working students lost jobs that supported their education; household budgets had to be split between essential needs and internet subscription; family-owned businesses closed; and scholarships were put in limbo. Consistent with these responses, students from lower-income brackets felt less capable of engaging in online learning. Some expressed that they might not be able to enroll next school year because they would not be able to afford the cost of medical education.

Almost three-fourths of the respondents belonged to families with an annual income of less than one million pesos, yet only one out of six declared being the beneficiary of a financial scholarship. Tuition alone would cost 24,000 to 150,000 pesos per semester [56]. The added expense of 
Fig. 1 Summary of responses to Likert scale questions

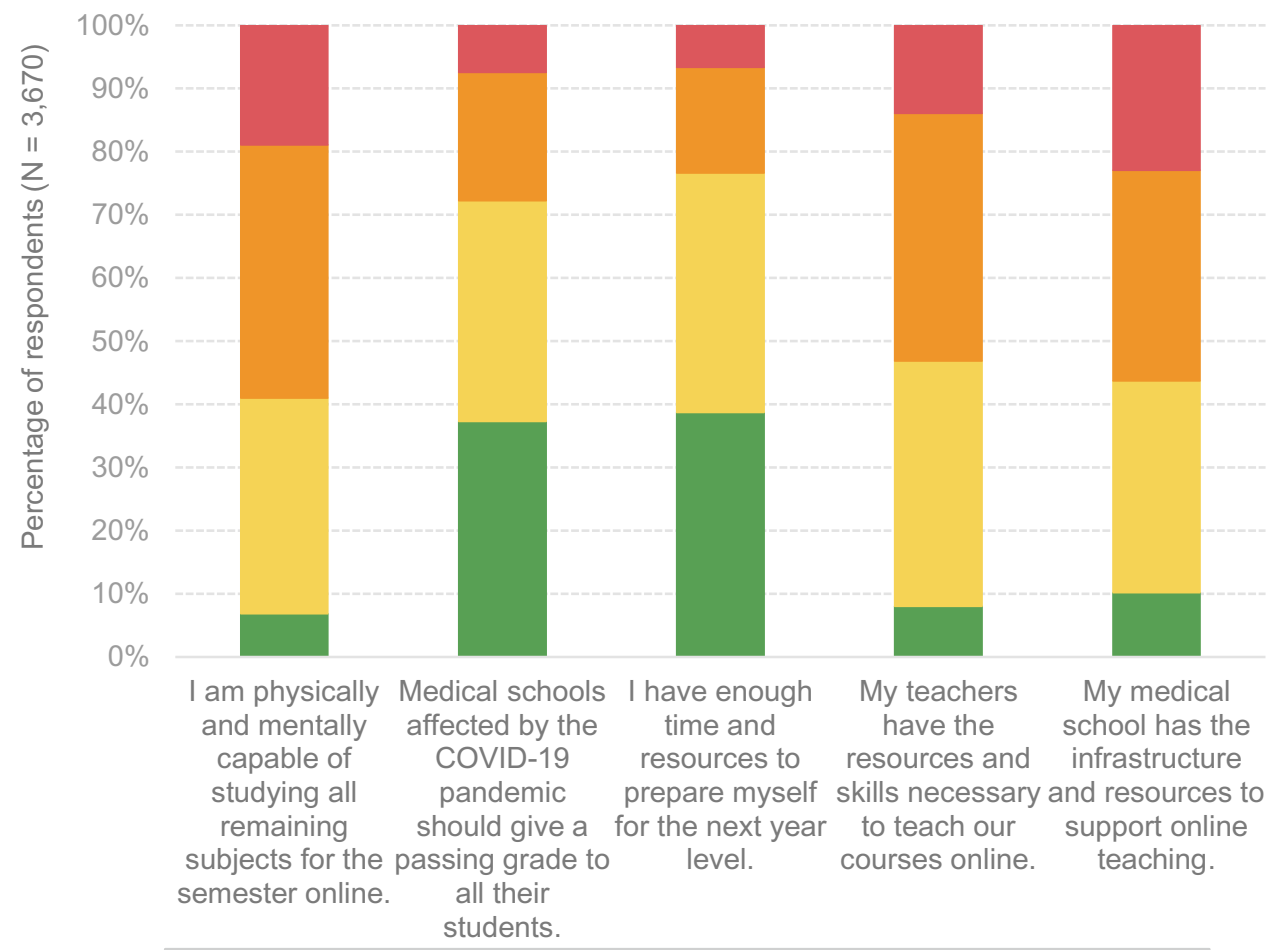

Strongly agree $\square$ Agree somewhat $\square$ Disagree somewhat $\square$ Strongly disagree online learning should not be underestimated. At the prevailing rate of 23 pesos per gigabyte and an estimated data consumption of 480 megabytes per 60-min video, a student who watches $4 \mathrm{~h}$ of online video lectures would need to spend 45 pesos daily [57]. To put the figures in context, minimum daily wage in the Philippines in May 2020 ranged from 230 to 450 pesos [58].

Our framework emphasizes that the challenges to online learning in developing countries are multifactorial and interrelated, especially during a global health crisis. As such, a holistic approach is necessary to adequately address these barriers.
Fig. 2 Frequency of occurrence of selected barriers to online learning among medical students in the Philippines during the COVID-19 pandemic
Difficulty adjusting learning styles

Need to fulfill responsibilities at home

Poor communication with educators

Limited space conducive for studying

Unreliable or no internet access

Mental health difficulties

Lack of technical skills

Need to work for extra income

No device or limited access

Lack of basic needs
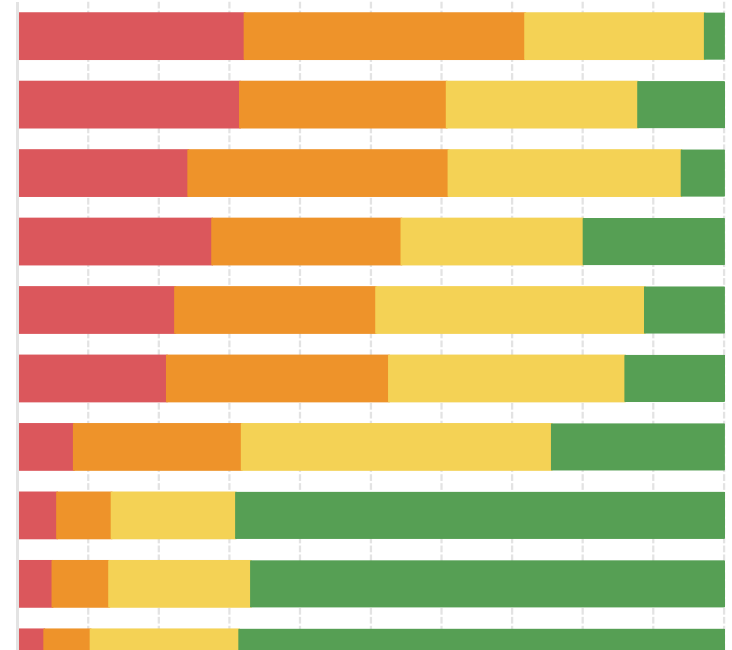

$\begin{array}{lllllllllll}0 \% & 10 \% & 20 \% & 30 \% & 40 \% & 50 \% & 60 \% & 70 \% & 80 \% & 90 \% & 100 \%\end{array}$

Percentage of respondents $(N=3,670)$

always $\quad$ Often $\quad$ Sometimes $\quad$ Never


Table 2 Comparison of self-assessment of capacity for online learning among student subgroups*

\begin{tabular}{|c|c|c|c|c|c|c|}
\hline \multirow{3}{*}{$\begin{array}{l}\text { Category } \\
\text { Medical school location }\end{array}$} & \multirow{3}{*}{$\begin{array}{l}\text { Subgroup } \\
\text { National Capital Region }\end{array}$} & \multirow{2}{*}{\multicolumn{2}{|c|}{$\begin{array}{l}\text { Number of } \\
\text { students and } \\
\text { percentage } \\
(N=3670)\end{array}$}} & \multicolumn{2}{|c|}{$\begin{array}{l}\text { Capacity for online } \\
\text { learning }\end{array}$} & \multirow{3}{*}{$\begin{array}{r}P \text { value } \\
0.792\end{array}$} \\
\hline & & & & \multirow{2}{*}{$\begin{array}{l}\text { Mean (SD) } \\
2.28(0.83)\end{array}$} & \multirow{2}{*}{$\frac{\text { Median }}{2}$} & \\
\hline & & 1726 & $47 \%$ & & & \\
\hline & Luzon, Visayas, and Mindanao & 1944 & $53 \%$ & $2.29(0.86)$ & 2 & \\
\hline \multirow[t]{2}{*}{ Medical school classification } & Public & 592 & $16 \%$ & $2.29(0.84)$ & 2 & 0.958 \\
\hline & Private & 3078 & $84 \%$ & $2.29(0.85)$ & 2 & \\
\hline \multirow[t]{2}{*}{ Year level } & 1 st and 2 nd year & 2168 & $59 \%$ & $2.21(0.84)$ & 2 & $<0.001$ \\
\hline & $3 \mathrm{rd}$ and 4 th year & 1502 & $41 \%$ & $2.41(0.85)$ & 2 & \\
\hline \multirow[t]{2}{*}{ Age } & $<30$ years old & 3570 & $97 \%$ & $2.28(0.85)$ & 2 & 0.002 \\
\hline & $\geq 30$ years old & 100 & $3 \%$ & $2.58(0.87)$ & 3 & \\
\hline \multirow[t]{3}{*}{ Gender $^{\mathrm{a}}$} & Male & 1109 & $30 \%$ & $2.45(0.86)$ & 2 & $<0.001$ \\
\hline & Female & 2468 & $67 \%$ & $2.22(0.84)$ & 2 & \\
\hline & Nonbinary/prefer not to say & 93 & $3 \%$ & $2.25(0.79)$ & 2 & \\
\hline \multirow[t]{2}{*}{ Family relationships } & Married/partnered or with children & 201 & $5 \%$ & $2.39(0.84)$ & 2 & 0.086 \\
\hline & Rest & 3467 & $94 \%$ & $2.28(0.85)$ & 2 & \\
\hline \multirow[t]{3}{*}{ Family income status ${ }^{\mathrm{b}, \mathrm{c}}$} & Low income & 1029 & $28 \%$ & $2.23(0.86)$ & 2 & $<0.001$ \\
\hline & Lower- and upper-middle income & 2306 & $63 \%$ & $2.29(0.83)$ & 2 & \\
\hline & High income & 302 & $8 \%$ & $2.47(0.95)$ & 2 & \\
\hline \multirow[t]{3}{*}{ Self-reported academic standing ${ }^{\text {b }}$} & Highest $25 \%$ in year level & 568 & $15 \%$ & $2.55(0.90)$ & 3 & $<0.001$ \\
\hline & Middle $50 \%$ in year level & 2581 & $70 \%$ & $2.27(0.83)$ & 2 & \\
\hline & Lowest $25 \%$ in year level & 521 & $14 \%$ & $2.09(0.82)$ & 2 & \\
\hline \multirow[t]{2}{*}{ Device ownership $^{* *}$} & One device or none & 375 & $10 \%$ & $2.25(0.93)$ & 2 & 0.167 \\
\hline & Two devices or more & 3295 & $90 \%$ & $2.29(0.84)$ & 2 & \\
\hline \multirow[t]{3}{*}{ Internet access } & No access & 58 & $2 \%$ & $2.07(0.95)$ & 2 & 0.030 \\
\hline & Prepaid mobile data & 696 & $19 \%$ & $2.25(0.87)$ & 2 & \\
\hline & Postpaid subscription & 2916 & $79 \%$ & $2.30(0.84)$ & 2 & \\
\hline \multirow[t]{3}{*}{ Hours spent on online learning, prior to pandemic ${ }^{b}$} & $4 \mathrm{~h} /$ week or less & 1552 & $42 \%$ & $2.21(0.85)$ & 2 & $<0.001$ \\
\hline & 5 to $24 \mathrm{~h} /$ week & 1848 & $50 \%$ & $2.33(0.83)$ & 2 & \\
\hline & 25 to $40 \mathrm{~h} /$ week & 270 & $7 \%$ & $2.47(0.94)$ & 3 & \\
\hline \multirow{3}{*}{$\begin{array}{l}\text { Hours allocated in school schedule for independent } \\
\text { study, prior to pandemic }\end{array}$} & $4 \mathrm{~h} /$ week or less & 1620 & $44 \%$ & $2.28(0.85)$ & 2 & 0.526 \\
\hline & 5 to $24 \mathrm{~h} /$ week & 1689 & $46 \%$ & $2.30(0.83)$ & 2 & \\
\hline & 25 to $40 \mathrm{~h} /$ week & 361 & $10 \%$ & $2.28(0.93)$ & 2 & \\
\hline
\end{tabular}

*The respondents were asked to indicate whether they perceived themselves to be "physically and mentally capable of studying all remaining subjects for the semester online." Possible responses were strongly disagree (1), disagree somewhat (2), agree somewhat (3), and strongly agree (4). Numeric equivalents were used to compute for mean and median responses for each subgroup. The means and standard deviation are indicated for ease of comparison, but $P$ values were obtained using nonparametric tests

${ }^{a}$ On post hoc analysis, males were significantly different from the rest

${ }^{b}$ On post hoc analysis, all subgroups were significantly different from each other

${ }^{\mathrm{c}}$ Annual income brackets: low income, Php 250,000 or less; lower-middle income, between Php 250,000 and Php 1 million; upper-middle income, between Php 1 and 2 million; high income, Php 2 million or more. Php 50 : US\$1

** Device may be a smartphone, tablet, laptop, or desktop computer

With these study findings, after review of proposed interventions from the respondents (see Supplementary Material B), we put forward the following recommendations for medical schools:

1. Conduct a needs assessment survey among medical students to identify those with limited access to technological resources.
2. Ensure open communication channels among administrators, educators, and students (e.g., through online town hall meetings). Guidelines and expectations must be clear, with provisions for improvement or worsening of the pandemic situation.

3. Whenever possible, implement an asynchronous mode of content delivery with minimal technical and data 
Table 3 Summary of student barriers to online learning during the COVID-19 pandemic

\begin{tabular}{|c|c|c|}
\hline Category & Barriers & Sample responses from students \\
\hline Technological barriers & $\begin{array}{l}\text { Lack of devices or limited access due to gadget sharing } \\
\text { Unreliable, slow, or no internet access } \\
\text { Lack of technical skills } \\
\text { Issues with the online learning platform }\end{array}$ & $\begin{array}{l}\text { "We only have one desktop computer, which is also used by } \\
\text { my brother, a student himself." } \\
\text { "I live outside the city where my school is located. The } \\
\text { internet connection is poor and unreliable." } \\
\text { "I only use mobile data and internet credit is expensive." } \\
\text { "Our school uses [REDACTED] as the main platform for } \\
\text { online learning. It crashes often." }\end{array}$ \\
\hline Individual barriers & $\begin{array}{l}\text { Difficulty adjusting learning styles } \\
\text { Mental health difficulties } \\
\text { Physical health issues } \\
\text { Practical concerns }\end{array}$ & $\begin{array}{l}\text { "Having a hard time understanding materials on my own." } \\
\text { "Lack of drive to study since it's different from the school } \\
\text { setup." } \\
\text { "Procrastination, distractions like unlimited internet } \\
\text { access." } \\
\text { "This pandemic gives nothing but uncertainty, stress, and } \\
\text { anxiety." } \\
\text { "Eye strain and headache from prolonged use of gadgets." } \\
\text { "My books, reference materials, and printer were all left in } \\
\text { my boarding house." }\end{array}$ \\
\hline Domestic barriers & $\begin{array}{l}\text { Limited space conducive for studying } \\
\text { Need to fulfill responsibilities at home } \\
\text { Conflicts within the family } \\
\text { Financial distress within the household } \\
\text { Need to work for extra income } \\
\text { Lack of basic needs }\end{array}$ & $\begin{array}{l}\text { "[Home] is not conducive [for studying] because of small } \\
\text { space and noisy background." } \\
\text { "I need to allocate a whole day just to buy groceries, medi- } \\
\text { cine, and other supplies because of the exhausting lines } \\
\text { in each." } \\
\text { "Relationship with family members is strained, so being in } \\
\text { the house for so long is emotionally and mentally tiring." } \\
\text { "I have to work for extra income since the main source of } \\
\text { income of our family is affected by the pandemic." } \\
\text { "We had no choice but to subscribe to an internet service } \\
\text { provider, despite my family being on a tight budget." }\end{array}$ \\
\hline Institutional barriers & $\begin{array}{l}\text { Administrative issues and lack of organization } \\
\text { Poor communication between learners and educators } \\
\text { Inadequate skills of educators } \\
\text { Poor quality of learning materials } \\
\text { Gaps in knowledge and skills from current teaching } \\
\text { methods } \\
\text { Excessive cognitive load } \\
\text { Limited opportunities to interact with peers } \\
\text { Policies and practices that neglect student welfare }\end{array}$ & $\begin{array}{l}\text { "Our school has not officially provided us with plans should } \\
\text { the current situation persist." } \\
\text { "We were promised leniency but our voices aren't heard." } \\
\text { "[Teachers] keep saying that they want to assess us but then } \\
\text { they never give feedback to the students." } \\
\text { "Lack of preparedness of educators to shift to online learn- } \\
\text { ing." } \\
\text { "Some professors just gave their files [presentation slides], } \\
\text { with no audio or presenter notes." } \\
\text { "Insufficient patient exposure for practical learning. In my } \\
\text { case, skills in missed clinical rotations such as orthope- } \\
\text { dics and radiology." } \\
\text { "Workload is far too much compared to when there were } \\
\text { face-to-face classes." } \\
\text { "[There is] the need for peers, for social connection and } \\
\text { motivation." } \\
\text { "My school requires two gadgets for them to watch on } \\
\text { the other gadget while I'm taking the exam on another } \\
\text { device." }\end{array}$ \\
\hline Community barriers & $\begin{array}{l}\text { Mobility restrictions due to community lockdown } \\
\text { Power interruptions } \\
\text { Sociopolitical concerns }\end{array}$ & $\begin{array}{l}\text { "Curfew hours [affect me because] I take my exams at my } \\
\text { friend's house for better internet connection." } \\
\text { "Rotational brownouts in provinces lasting for about } 2 \text { to } 6 \\
\text { hours." } \\
\text { "As a concerned Filipino, with all that's happening in the } \\
\text { government, it is so hard to just hunch over these books } \\
\text { without being distracted." }\end{array}$ \\
\hline
\end{tabular}


requirements. Smartphone compatibility remains essential.

4. Create opportunities for meaningful interaction with peers and educators. These may include synchronous sessions to answer student queries on complex topics, asynchronous discussion boards, periodic feedback on assessments, and mentoring sessions.

5. During the transition phase, maximize use of curated online resources that are available for free or with an institutional subscription. To sustain the online curriculum, support and train faculty on content creation, management, and delivery. Invest in technical support.

6. Adjust assessment measures and other coursework, keeping them aligned with and proportionate to desired learning outcomes. More frequent formative tests are preferred over a single, high-stakes examination.

7. Extend leniency to students who bear additional responsibilities at home. For example, they could be given reasonable extra time to complete tasks. If they are unable to attend synchronous sessions, alternative learning activities must be offered.

8. Provide proactive psychosocial support for the students. Develop mental wellness programs with a focus on teaching positive coping mechanisms to deal with stressors.

9. Give discounts on tuition and offer scholarships to cushion the pandemic's economic impact. Advocate for greater subsidies from the government.

10. Develop bridging programs and prepare for gradual return to clinical activities. Consider putting up simulation laboratories and other infrastructure that will allow face-to-face learning with social distancing.

\section{Limitations}

Our study was subject to selection bias, wherein students with no internet access and those who had been severely affected by the pandemic may not have received our survey. Social distancing measures had already been in place during the study period, preventing the distribution of questionnaires in person. Thus, the reported deficit in technological resources was likely an underestimate. Self-reporting bias may have also affected responses. Another limitation was the use of a self-developed survey instrument, mainly due to the acuity of circumstances, urgent need to gather data, restrictions in mobility, and limited resources available to us during the early phase of the pandemic in the Philippines. Nevertheless, the comprehensive data we had been able to capture from a large sample of medical students addressed an important need among medical schools and educators nationwide.
Lastly, our study focused on identifying barriers to online learning and their relative importance from the point of view of medical students. We did not delve into student expectations, motivations, and perceptions of online education, which also influence their overall learning experience.

\section{Conclusion}

Medical students in the Philippines confronted technological, individual, domestic, institutional, and community barriers as they tried to adapt to online learning. Some of these barriers are transient and expected to resolve with the global health crisis; others may persist or have long-term repercussions. Moreover, the economic consequences of the pandemic heightened disparities in medical education, often in favor of those with greater access to resources. Without appropriate intervention, barriers to online learning would not just affect the education and training of future physicians. On a wider scale, even the nation's delivery of healthcare services may be disrupted. By implementing studentcentered interventions, medical schools and educators play a significant role in addressing these challenges during the COVID-19 pandemic and beyond.

Supplementary Information The online version contains supplementary material available at https://doi.org/10.1007/s40670021-01231-z.

Acknowledgements The authors would like to acknowledge the assistance of the Commission on Higher Education's Office of Programs and Standards Development, and the support of the Association of Philippine Medical Colleges-Student Network, the Asian Medical Students' Association-Philippines, and the student councils of the following medical schools: Ago Medical and Educational Center-Bicol Christian College of Medicine, Ateneo De Zamboanga University, Bicol University, Cagayan State University Carig, Cebu Doctors' University, Cebu Institute of Medicine, Cebu Normal University, De La Salle Medical and Health Sciences Institute, Remedios T. Romualdez Medical Foundation, San Beda University, Silliman University, University of the Philippines Manila, West Visayas State University, and Xavier University.

Author Contribution REB conceptualized the study, drafted the survey instrument, wrote the first draft, and prepared the final manuscript. NRIA, MBCB, RECM, LGTR, JJS, CJST, and CAC revised the survey instrument, reviewed relevant literature, and performed thematic analysis on free-text responses. All authors participated in the survey distribution, data collection, and data interpretation. JCBR performed all statistical analyses. All authors read, made substantial contributions to, and approved the final manuscript.

Data Availability The datasets used and/or analyzed in the current study are available from the corresponding author on reasonable request. 


\section{Declarations}

Ethics Approval The University of the Philippines Manila Research Ethics Board reviewed the study protocol and issued a certificate of exemption (UPMREB 2020-281-EX).

Consent to Participate Consent was obtained from participants at the start of the survey.

Conflict of Interest The authors declare that they have no conflict of interest.

\section{References}

1. Ahmed H, Allaf M, Elghazaly H. COVID-19 and medical education. Lancet Infect Dis. 2020;20(7):777-8.

2. Muller D, Parkas V, Amiel J, Anand S, Cassese T, Cunningham $\mathrm{T}$, et al. Guiding principles for undergraduate medical education in the time of the COVID-19 pandemic. Med Teach. 2020 Nov $3 ; 1-5$.

3. Wang S, Dai M. Status and situation of postgraduate medical students in China under the influence of COVID-19. Postgrad Med J. 2020;:postgradmedj-2020-137763.

4. Gallagher TH, Schleyer AM. "We signed up for this!" - student and trainee responses to the Covid-19 pandemic. N Engl J Med. 2020;382(25):e96.

5. Tolsgaard MG, Cleland J, Wilkinson T, Ellaway RH. How we make choices and sacrifices in medical education during the COVID-19 pandemic. Med Teach. 2020;42(7):741-3.

6. Moore JL, Dickson-Deane C, Galyen K. e-Learning, online learning, and distance learning environments: are they the same? Internet High Educ. 2011;14(2):129-35.

7. Ruiz JG, Mintzer MJ, Leipzig RM. The impact of E-learning in medical education. Acad Med. 2006;81(3):207-12.

8. Ferrel MN, Ryan JJ. The impact of COVID-19 on medical education. Cureus. 2020;12(3):e7492.

9. Pather N, Blyth P, Chapman JA, Dayal MR, Flack NAMS, Fogg QA, et al. Forced disruption of anatomy education in Australia and New Zealand: an acute response to the Covid-19 pandemic. Anat Sci Educ. 2020;13(3):284-300.

10. Calhoun KE, Yale LA, Whipple ME, Allen SM, Wood DE, Tatum RP. The impact of COVID-19 on medical student surgical education: implementing extreme pandemic response measures in a widely distributed surgical clerkship experience. Am J Surg. 2020;220(1):44-7.

11. Howlett D, Vincent T, Gainsborough N, Fairclough J, Taylor N, Cohen J, et al. Integration of a case-based online module into an undergraduate curriculum: what is involved and is it effective? e-Learning. 6 ed. 2009 Jan;6(4):372-84.

12. Chen BY, Kern DE, Kearns RM, Thomas PA, Hughes MT, Tackett $\mathrm{S}$. From modules to MOOCs: application of the six-step approach to online curriculum development for medical education. Acad Med. 2019;94(5):678-85.

13. Ellman MS, Schwartz ML. Online learning tools as supplements for basic and clinical science education. J Med Educ Curric Dev. 2016 Jan;3:JMECD.S18933.

14. Maggio LA, Tannery NH, Chen HC, Cate OT, O’Brien B. Evidence-based medicine training in undergraduate medical education. Acad Med. 2013;88(7):1022-8.

15. Ellman MS, Schulman-Green D, Blatt L, Asher S, Viveiros D, Clark J, et al. Using online learning and interactive simulation to teach spiritual and cultural aspects of palliative care to interprofessional students. J Palliat Med. 2012;15(11):1240-7.

16. George PP, Papachristou N, Belisario JM, Wang W, Wark PA, Cotic Z, et al. Online eLearning for undergraduates in health professions: a systematic review of the impact on knowledge, skills, attitudes and satisfaction. J Glob Health. 2014;4(1):010406.

17. Frehywot S, Vovides Y, Talib Z, Mikhail N, Ross H, Wohltjen $\mathrm{H}$, et al. E-learning in medical education in resource constrained low- and middle-income countries. Hum Resour Health. 2013;11(1):4-15.

18. Singh K, Srivastav S, Bhardwaj A, Dixit A, Misra S. Medical education during the COVID-19 pandemic: a single institution experience. Indian Pediatr. 2020;57(7):678-9.

19. Abbasi S, Ayoob T, Malik A, Memon SI. Perceptions of students regarding e-learning during Covid-19 at a private medical college. Pak J Med Sci. 2020 May;36(COVID19-S4):S57-S61.

20. Nepal S, Atreya A, Menezes RG, Joshi RR. Students' perspective on online medical education amidst the COVID-19 pandemic in Nepal. J Nepal Health Res Counc. 2020;18(3):551-5.

21. Al-Balas M, Al-Balas HI, Jaber HM, Obeidat K, Al-Balas H, Aborajooh EA, et al. Distance learning in clinical medical education amid COVID-19 pandemic in Jordan: current situation, challenges, and perspectives. BMC Med Educ. 2020;20(1):341.

22. Alsoufi A, Alsuyihili A, Msherghi A, Elhadi A, Atiyah H, Ashini A, et al. Impact of the COVID-19 pandemic on medical education: medical students' knowledge, attitudes, and practices regarding electronic learning. PLoS ONE. 2020;15(11):e0242905.

23. Bautista D, Lopez ML. Timeline: how the Philippines is handling COVID-19. https://www.cnnphilippines.com/news/2020/4/21/ interactive-timeline-PH-handling-COVID-19.html. Accessed 30 May 2020.

24. Association of Philippine Medical Colleges Student Network. Letter to Commission on Higher Education. https://www.facebook. com/StudentNetworkAPMC/. Accessed 30 May 2020.

25. Regmi K, Jones L. A systematic review of the factors - enablers and barriers - affecting e-learning in health sciences education. BMC Med Educ. 2020;20(1):91.

26. Childs S, Blenkinsopp E, Hall A, Walton G. Effective e-learning for health professionals and students--barriers and their solutions. A systematic review of the literature--findings from the HeXL project. Health Info Libr J. 2nd ed. 2005 Dec;22 Suppl 2(s2):20-32.

27. O'Doherty D, Dromey M, Lougheed J, Hannigan A, Last $\mathrm{J}$, McGrath D. Barriers and solutions to online learning in medical education - an integrative review. BMC Med Educ. 2018;18(1):130.

28. Global Health Workforce Alliance, World Health Organization. Health workforce 2030: towards a global strategy on human resources for health. 2015. Geneva: World Health Organization; 2015.

29. Coronavirus Pandemic Data Explorer - Philippines. Our World in Data. https://ourworldindata.org/coronavirus-dataexplorer?zoomToSelection $=$ true $\&$ time $=$ earliest..latest $\&$ country $=$ $\sim$ PHL\&region $=$ World \& casesMetric $=$ true \&interval $=$ smoothed $\&$ hideControls $=$ true \&smoothing $=7 \&$ pickerMetric $=$ total_cases $\&$ pickerSort=desc. Accessed 21 Jan 2021.

30. Population, total - Philippines. The World Bank. https://data. worldbank.org/indicator/SP.POP.TOTL?locations=PH. Accessed cited 20 Dec 2020.

31. Commission on Higher Education. Policies, standards, and guidelines for the Doctor of Medicine (M.D.) program. https://ched.gov. ph/wp-content/uploads/2017/10/CMO-18-s.-2016.pdf. Accessed 30 May 2020.

32. Atienza MA. The eclectic nature of Philippine medical curricula. In: Arcadio RL, Leopando ZE, editors. Current Status of Basic 
Medical Education in the Philippines 2016. Taguig City: National Academy of Science and Technology, Phils; 2017. pp. 72-7.

33. Physician licensure examination results. Professional Regulation Commission. https://prc.gov.ph/. Accessed 2020.

34. Barteit S, Guzek D, Jahn A, Bärnighausen T, Jorge MM, Neuhann F. Evaluation of e-learning for medical education in low- and middle-income countries: a systematic review. Comput Educ. 2019;7(145):103726.

35. Andersson A, Grönlund A. A conceptual framework for E-learning in developing countries: a critical review of research challenges. Electron J Inf Syst Dev Ctries. 2017;38(1):1-16.

36. Arcadio RL, Leopando ZE, editors. Current status of basic medical education in the Philippines 2016. Taguig City: National Academy of Science and Technology, Phils; 2017. https://issuu. com/maanalto/docs/final_7_csbmep_2016. Accessed 30 May 2020.

37. Daroedono E, Siagian FE, Alfarabi M, Cing JM, Arodes ES, Sirait $\mathrm{RH}$, et al. The impact of COVID-19 on medical education: our students perception on the practice of long distance learning. Int J Community Med Public Health. 2020;7(7):2790-7.

38. Mukhtar K, Javed K, Arooj M, Sethi A. Advantages, limitations and recommendations for online learning during COVID-19 pandemic era. Pak J Med Sci. 2020 May;36(COVID19-S4):S27-S31.

39. Fleming ND, Mills C. Not another inventory, rather a catalyst for reflection. To Improve the Academy. 2017;11(1):137-55.

40. Grunwald T, Corsbie-Massay C. Guidelines for cognitively efficient multimedia learning tools: educational strategies, cognitive load, and interface design. Acad Med. 2006;81(3):213-23.

41. Cook DA, Levinson AJ, Garside S, Dupras DM, Erwin PJ, Montori VM. Instructional design variations in internet-based learning for health professions education: a systematic review and meta-analysis. Acad Med. 2010;85(5):909-22.

42. Broadbent J, Poon WL. Self-regulated learning strategies \& academic achievement in online higher education learning environments: A systematic review. Internet High Educ. 2015 Oct $1 ; 27(\mathrm{C}): 1-13$.

43. Wang $\mathrm{C}$, Xie A, Wang W, Wu H. Association between medical students' prior experiences and perceptions of formal online education developed in response to COVID-19: a cross-sectional study in China. BMJ Open. 2020;10(10):e041886.

44. Aker S, Midık Ö. The views of medical faculty students in Turkey concerning the COVID-19 pandemic. J Community Health. 2020;45(4):684-8.

45. Arima M, Takamiya Y, Furuta A, Siriratsivawong K, Tsuchiya $\mathrm{S}$, Izumi M. Factors associated with the mental health status of medical students during the COVID-19 pandemic: a crosssectional study in Japan. BMJ Open. 2020;10(12):e043728.
46. Lyons Z, Wilcox H, Leung L, Dearsley O. COVID-19 and the mental well-being of Australian medical students: impact, concerns and coping strategies used. Australas Psychiatry. 2020;28(6):649-52.

47. Cao W, Fang Z, Hou G, Han M, Xu X, Dong J, et al. The psychological impact of the COVID-19 epidemic on college students in China. Psychiatry Res. 2020;287(10224):112934.

48. Medina BT-G. The Filipino family. Quezon City: University of the Philippines Press; 2001.

49. Morillo HM, Capuno JJ, Mendoza AM. Views and values on family among Filipinos: an empirical exploration. Asian J Soc Sci. 2013;41(1):5-28.

50. Tarroja MCH. Revisiting the definition and concept of Filipino family: a psychological perspective. Philipp J Psychol. 2010;43(2):177-93

51. Ashokka B, Ong SY, Tay KH, Loh NHW, Gee CF, Samarasekera DD. Coordinated responses of academic medical centres to pandemics: sustaining medical education during COVID-19. Med Teach. 2020;42(7):762-71.

52. Theoret $\mathrm{C}$, Ming $\mathrm{X}$. Our education, our concerns: the impact on medical student education of COVID-19. Med Educ. 2020;54(7):591-2.

53. Hofmann H, Harding C, Youm J, Wiechmann W. Virtual bedside teaching rounds with patients with COVID-19. Med Educ. 2020;54(10):959-60.

54. Kim S. The future of E-Learning in medical education: current trend and future opportunity. J Educ Eval Health Prof. 2006;3(3):3.

55. Dancel R. Philippines' unemployment rate at record high in April. The Straits Times. https://www.straitstimes.com/asia/se-asia/ philippines-unemployment-rate-at-record-high-in-april. Accessed 14 June 2020.

56. Recto RG. Full tuition subsidy to medical students enrolled in state universities and colleges (SUCs) act. https://www.senate.gov. ph/lisdata/3174328591!.pdf. Accessed 30 May 2020.

57. Data calculator. Smart communications. https://smart.com.ph/ Corporate/data-calculator. Accessed 30 May 2020.

58. National Wages and Productivity Commission. Current real minimum wage rates. Department of Labor and Employment. https://nwpc.dole.gov.ph/stats/current-real-minimum-wage-rates/. Accessed 14 June 2020.

Publisher's Note Springer Nature remains neutral with regard to jurisdictional claims in published maps and institutional affiliations. 